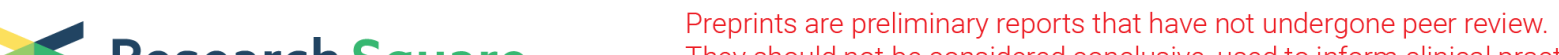 Research Square They should not be considered conclusive, used to inform clinical practice, or referenced by the media as validated information.
}

\section{Anatomical Boundaries in Plant Roots Form Important Barriers for Selection of the Soil Microbiome}

\section{Yi Zhou}

University of Adelaide AFW: The University of Adelaide School of Agriculture Food and Wine Yanli Wei

Qilu University of Technology

Zhongjuan Zhao

Qilu University of Technology

Jishun Li

Qilu University of Technology

\section{Hongmei Li}

Qilu University of Technology

\section{Peizhi Yang}

Qilu University of Technology

\section{Shenzhong Tian}

Qilu University of Technology

\section{Maarten Ryder}

University of Adelaide AFW: The University of Adelaide School of Agriculture Food and Wine

\section{Ruey Toh}

University of Adelaide AFW: The University of Adelaide School of Agriculture Food and Wine

\section{Hetong Yang}

Qilu University of Technology

Matthew Denton ( $\square$ matthew.denton@adelaide.edu.au )

University of Adelaide https://orcid.org/0000-0002-2804-0384

\section{Research}

Keywords: microbe, perennial plant, plant-growth promoting bacteria, N2 fixation

Posted Date: November 15th, 2021

DOI: https://doi.org/10.21203/rs.3.rs-1057148/v1 
License: (c) (i) This work is licensed under a Creative Commons Attribution 4.0 International License. Read Full License 


\section{Abstract}

\section{Background}

The microbiome in plant-soil systems has a significant influence in promoting plant growth. The extent of selectivity that the plant exerts on the microbiome in the continuum of internal plant tissues is not well understood. This study analysed the root microbiome of a legume, Melilotus officinalis (L.) Pall., sweet clover, and focused on dynamic shifts in the microbial community structure through the niches of bulk soil, rhizosphere, periderm, phloem and xylem, and further examined the effects of environmental factors, root exudates and root cell wall development on the microbiome assemblages in different root compartments.

\section{Results}

Young and mature plants were sampled at 24 field sites and the microbial communities in different niches from bulk soil and rhizosphere through to root compartments were analysed by 16S rRNA gene sequencing. The microbiome composition changed from periderm to phloem to a greater extent than across other boundaries ( 0.95 vs 0.71 based Bray-Curtis distance). Variation in microbiome composition was associated with geographic distance and soil properties for the bulk soil, rhizosphere and periderm niches. The composition of root exudate compounds were correlated with the rhizosphere microbiome assemblages in mature and young plants. The endophyte communities that occupied the phloem and xylem were most conserved and were independent of growing environments and root exudation. Symbiotic rhizobia able to nodulate $M$. officinalis were prominent colonisers of the periderm $(\sim 15 \%)$ and xylem ( 6.2\%), but were only a minor component in other soil-related niches (0.1\%-2.5\%). In xylem tissues, endophyte diversity was correlated with the total cell wall and lignin content across the sampled sites $(r=0.29-0.62)$.

\section{Conclusions}

Our results demonstrate that selection of microbiome constituents occurs at different boundaries through bulk soil, rhizosphere, periderm, phloem and xylem, and is especially strong across the periderm boundary. The conserved endophyte community in the innermost tissues (phloem and xylem) was identified, and will be advantageous to the development of specific beneficial microbial inoculants.

\section{Background}

The rhizosphere is a hot spot of interaction between the soil microbiome and plant root metabolism. The roles of rhizosphere microbes have been widely demonstrated, including in contributions to plant growth and health via nutrient mobilization, phytohormone production, modifying the activity of soilborne pathogens, and altering plant abiotic stress tolerance [1-3]. However, the structure of the rhizosphere microbiome is unstable during the plant's lifespan, as plant roots are directly exposed to dense populations of indigenous soil bacteria that exhibit great biodiversity, and are sensitive to environmental 
changes [4,5]. Endophyte communities that colonize the interior root tissues of the host plant are likely to show a more consistent assemblage structure than the microbial communities inhabiting the rhizosphere $[6,7]$.

The selective forces exerted by host plants toward the microbiome increase along the continuum between the rhizosphere soil and the root tissue [8]. For example, host phylogenetic relatedness and rootassociated microbiome distance were strongly correlated in the endosphere, but were poorly correlated or uncorrelated in the rhizosphere in 30 plant species [9] and 18 grass species [10], respectively. A three-step model has been proposed to describe the dynamics of the plant's selective enrichment for microbes from the external soil to internal root habitats [11]. The model includes rhizosphere processes (e.g., root exudation and rhizodeposition), rhizoplane processes (e.g., biofilm formation eliciting specific adhesion mechanisms), and, finally, endosphere selection (which could include the modulating influence of the plant immune system). This model has been widely applied to explain the assemblage of root-associated microbiomes influenced by different soil environments, plant genotypes, and development stages in the annual plants Arabidopsis, rice, soybean, and barley [12-15].

Compared with annual plants, where the primary root system has a short lifespan, and where the majority of research has been undertaken, structures of root-associated microbiomes in perennial plants, especially the endophytic communities, have been less studied. In general, perennial plants are able to form secondary structures in the root tissue where secondary vascular tissue (i.e. periderm, secondary xylem and secondary phloem) replaces the anatomical parts of the primary root, i.e. epidermis, cortex, and endodermis [16]. Previous studies on grapevine, using fluorescence in situ hybridization, observed the existence of labelled bacterial strains of Sphingomonadaceae and Enterobacteriaceae in the rhizosphere, epidermis, cortex and central cylinder, and concluded that colonization patterns through root anatomical compartments were strain dependent [17]. Similarly, cortical cells, endodermis, and xylem vessels of grapevine roots harboured inoculant Burkholderia sp. strains via both intracellular and intercellular colonization [18]. Although populations of individual microbial strains have been studied, whole microbial community structure in different anatomical compartments of plant endophytic zones have seldom been evaluated in perennials. The colonization of microbial communities through different layers of the secondary root tissue is likely to be complex and governed by stochastic events and deterministic processes of colonization. Potential contributing factors include open wound sites on the root system, sites where lateral roots emerge, lenticels, the mobility and secretion of cell-wall degrading enzymes from diverse bacteria and fungi, and responses of the plant immune system to the destructive actions of pests and pathogens $[6,19]$.

The assembly of the endophytic microbiome can be regulated by plant factors such as root exudation activity and cell wall development processes in root tissue. As plants secrete $17-40 \%$ of photosynthetically fixed carbon as root exudates [20], these can act as major carbon sources and/or chemo-attractants for microbes in the rhizosphere, favouring root colonization, and shaping the endophytic community $[5,21]$. In addition, the inner compartment of a mature root system, following secondary development, has more woody tissue and dead cells from cell wall lignification, which appears 
to lead to a conserved microbiome among different plants and across niches. For example, $40 \%$ of the bacterial taxa in the Arabidopsis endosphere also colonized the dead wood of tree species such as Betula and Fagus [13]. Therefore, cell wall components might play important roles in determining the structure of root-inhabiting microbiota. Previous studies on root-associated microbiota have revealed a high degree of microbial dynamism from the seedling stage through to maturity in rice [22], sorghum [23] and Arabidopsis [24], while the mechanisms driving the change in microbiome structure during the plant's life cycle are poorly understood, especially in regard to root metabolism and development of root structure.

In contrast to the majority of plants, some legumes can develop a beneficial root endosymbiosis with symbiotic rhizobia and form nitrogen-fixing nodules [25]. Rhizobial infection induces the rapid growth of epidermal, cortical, and pericycle cells, with a relative abundance of 60 to $90 \%$ symbiotic rhizobia observed in soybean nodules [15]. An exponential increase in populations of symbiotic rhizobia through bulk soil, rhizosphere soil, root tissue and nodule tissue has been reported in different legume species [26]. However, the distribution of symbiotic rhizobia among anatomical compartments within root tissue have not been studied in detail.

Melilotus officinalis is a forage legume, characterised by salt tolerance and the development of a thick tap root with clear secondary anatomical compartments that are formed within a short growing period. Young (primary growth) and mature (secondary growth) plants of $M$. officinalis were sampled across 24 sites to evaluate microbiome assemblages from the exterior to the interior niches of the root. The objectives of the present study were (1) to understand the microbiome diversity, composition and the abundance of key components in bulk soil, rhizosphere soil, and endospheric compartments including the periderm, phloem, and xylem; and (2) to evaluate the selective forces applied by host plants that shape the microbiome in each niche and to compare the effects of geographic and environmental variability.

\section{Methods}

This study was situated in the Yellow River Delta (YRD) region of Shandong Province, China. As a sediment-laden river, the Yellow River carries the most sediment of any river in the world [27], and forms a large area of floodplain and wetland landscape with frequent channel migrations [28]. M. officinalis is widely distributed in the YRD, possibly due to its high salt tolerance and biological $\mathrm{N}_{2}$ fixation capability [29]. In the present study, M. officinalis were sampled from 24 sites across the YRD (Fig. S1). At each site, plants were excavated from a $\sim 200 \mathrm{~m}^{2}$ area, including young plants (one-year old, 8 to $10 \mathrm{~cm}$ height, and $\sim 1 \mathrm{~mm}$ tap root diameter) and mature plants (two-year old, 30 to $50 \mathrm{~cm}$ height, and $10 \mathrm{~mm}$ tap root diameter). Both young and mature plants were at vegetative growth stage when sampling. Bare soils next to the sampled plants were collected as the bulk soil.

\section{Microbial community analysis}

The rhizosphere soil was sampled based on the protocol of Bulgarelli et al [13]. Firstly, root sections taken from 2 to $12 \mathrm{~cm}$ depth in the soil profile were shaken until there was approximately $1 \mathrm{~mm}$ soil attached to 
the roots. Then, roots with attached soil were washed in Falcon tubes filled with PBS buffer (135 mM $\mathrm{NaCl}, 2.7 \mathrm{mM} \mathrm{KCl}, 1.5 \mathrm{mM} \mathrm{KH}_{2} \mathrm{PO}_{4}$, and $8 \mathrm{mM} \mathrm{K}_{2} \mathrm{HPO}_{4}, \mathrm{pH}$ 7.2) by shaking at $150 \mathrm{rpm}$ for $30 \mathrm{~min}$. The soil suspension was centrifuged at $8000 \mathrm{rpm}(14310 \mathrm{~g})$ for $5 \mathrm{~min}$, and the pellet was collected as rhizosphere soil. The washed roots were transferred to a new Falcon tube, and cleaned further using a sonicator (180W, 20 min, SCIENTZ, SB-3200DT, China). As observed by Edwards et al [14], it is difficult to remove all the bacteria adhering to the root surface without damaging the epidermis, which was likely to have occurred in the present study. Therefore, bacteria that were tightly attached to the root after the sonication process were considered to be the microbial community from the periderm zone.

After sonication, nodules were separated from the root system, and tap roots were processed further. The whole tap root of the young plants was considered as the endosphere. For the mature plants, the $10 \mathrm{~cm}$ sampled tap root was cut into $5 \times 2 \mathrm{~cm}$ sections, and each section was longitudinally split into three anatomical compartments including the periderm, phloem and xylem zones (Fig. 1) using a sterilised microtome (HistoCore AUTOCUT, Leica Biosystems, Wetzlar, Germany). All samples were stored at $-80{ }^{\circ} \mathrm{C}$ until DNA extraction.

DNA was extracted from the samples ( $0.4 \mathrm{~g}$ for soil samples and $0.5 \mathrm{~g}$ for plant tissues) using the PowerSoil DNA isolation kit (MoBio Labroratories, Carlsbad, CA, USA) according to the manufacturer's instructions. DNA from the same niche of the 10 young roots or 10 mature roots was combined as one sample for the site. In total, there were 216 samples for microbiome analysis: 9 rhizocompartments (bulk soil, rhizosphere - mature plant, nodules - mature plant, periderm - mature plant, phloem - mature plant, xylem - mature plant, rhizosphere - young plant, nodules - young plant, and endosphere - young plant) at each of the 24 sites.

The hypervariable V3-V4 region of the bacterial 16S rRNA gene was amplified using the primers 341F (5'CCTACGGGNGGCWGCAG -3') and 805R (5'- GACTACHVGGGTATCTAATCC -3') [30]. A Qubit fluorometer (version 2.0, ThermoFisher Scientific, USA) was used to quantify the extracted DNA. PCR products were purified using magnetic DNA clean beads (ThermoFisher Scientific, USA) according to the manufacturer's instructions, and then sequenced on the Illumina Miseq ${ }^{\mathrm{TM}}$ platform with $300 \mathrm{bp}$ length of PE reads. All the sequence data generated in the present study have been uploaded on National Center for Biotechnology Information with the project ID: PRJNA603423 and accessions ID: SAMN13931281.

Sequences of microbiome 16S rRNA genes were analysed on the Quantitative Insights Into Microbial Ecology 2 (QIIME2) platform [31]. Firstly, raw reads were demultiplexed ("q2-demux" plugin), and then trimmed and quality controlled ("q2-cutadapt" plugin). Representative read was picked using DADA2 denoising algorithm ("q2-dada2" plugin [32]) to generate an amplicon sequence variants (ASVs) table. ASVs were annotated against the SILVA reference database (vs. 132 [33]). ASVs assigned to chloroplasts or mitochondria were regarded as organellar ASVs, and were removed from the analysis. Low frequent ASVs (appearing in less than 9 samples, $5 \%$ of the total sample number) were also removed.

\section{Plant and soil analysis}


At each site, 30 mature plants and 30 young plants were collected for analysis of cell wall components of root tissues. Roots were surface cleaned, and horizontal fractions were separated, both as described in microbiome analysis. The total cell wall and lignocellulose content were determined by a dry-weightbased neutral detergent fibre (NDF) method and acid detergent fibre (ADF) method, respectively. Afterwards, the permanganate procedure was applied to estimate lignin and cellulose contents in ADF [34]. The bulk soils collected at each site were analysed for chemical properties (total N, P, K, organic carbon, pH and EC) and physical properties (texture) according to the protocol of Rayment and Lyons [35].

\section{Root exudate analyses}

Root exudates were collected using the methods of Aulakh et al [36] and Dietz et al [37], targeting plants grown in field conditions. Five mature plants and 5 young plants were excavated at random at each site. Soils attached to the roots were removed by washing twice, firstly using tap water, and then sterilised deionized water. The intact roots of the plants were transferred into two tubes containing $200 \mathrm{ml}$ sterilised water, one for 5 mature plants and the other for 5 young plants. After 2 hours, the collected exudate solution was filtered through a filter paper (Whatman No. 42$)$, and a membrane filter $(0.45 \mu \mathrm{m})$ to remove root detritus and microbes. The filtrates were frozen and stored at $-80^{\circ} \mathrm{C}$ until further processing.

Carbohydrates and amino acids in the collected root exudates were analysed using the method of Conselvan et al [38]. Briefly, gas chromatography (GC) was performed to measure carbohydrates and sugars on an Agilent 6890 Gas Chromatograph with QQQ 7000 Mass selective detector with a HP5 column ( $0.25 \mathrm{~mm}$ i.d., $30 \mathrm{~m}, 0.25 \mathrm{~mm}$ film thickness; Agilent Technologies, Santa Clara, United States). Split injection was made at $300^{\circ} \mathrm{C}$ with an initial oven temperature program of $60^{\circ} \mathrm{C}$ for $2 \mathrm{~min}$, ramping to $300^{\circ} \mathrm{C}$ at a rate of $10^{\circ} \mathrm{C} \mathrm{min}^{-1}$ and maintained for $10 \mathrm{~min}$. Column flow rate was maintained at $1.5 \mathrm{~mL}$ $\mathrm{min}^{-1}$. Amino acids in root exudates were analysed by LC-MS on a 1290 Infinity LC system coupled to a 6520 QTOF Mass selective detector (Agilent Technologies, Santa Clara, United States). A 3.5 uL sample was injected into a Zorbax SB-C18 column $(2.1 \times 150 \mathrm{~mm}, 3.5 \mu)$. The QTOF was set up as the low mass range ( $<1700 \mathrm{AMU})$, scan mode $(60-1000 \mathrm{~m} / \mathrm{z})$, and positive ion mode. Peak integration and the relative quantities were calculated using Mass Hunter software (version B.07.01, Agilent Technologies). The measured abundances of root exudate compounds were adjusted for the trapping period $(2 \mathrm{~h})$ and dry weight of the root samples.

\section{Statistical analysis}

The microbiome present in nodules was dominated by one ASV (ASV0), which was annotated as Ensifer, accounting for over $97 \%$ relative abundance, so nodule samples were not included in the composition and diversity analysis, and ASVO was regarded as being the symbiotic rhizobia of M. officinalis. The statistical analysis was carried out using R software version 3.4.3 [39]. The trimmed mean of the Mvalues method [40] from the Vegan package (version 2.4-5 [41]) was applied to normalise the various library sizes between samples. Using the normalised data, principal coordinate analyses (PCoA) were conducted, based on Bray-Curtis distances. To test the effects of niche on ASV composition, 
permutational multivariate analyses of variance (PERMANOVA) was run with maximum 999 permutations using the adonis function. Similarity percentage analysis (SIMPER) on Bray-Curtis distance with 999 permutations was conducted to identify the contribution of each ASV to the dissimilarity of microbiome composition between two neighbouring niches (Vegan package). The Shannon diversity index of the ASVs in each sample was calculated using the iNEXT package in R [42], which provides asymptotic estimation by rarefying data to account for differences in sequencing depth.

Relative abundances of taxonomic groups at the phylum and ASV level were compared between different niches using the Statistical Analysis of Metagenomic Profiles (STAMP) package [43]. The BenjaminiHochberg FDR option was selected as the multiple test correction method.

In each of the sampled niches, a distance-decay model was used to test the relationship between microbiome similarity and geographic distance between sites. The model was described as: $\log _{10}(S)=$ $(-2 z) * \log _{10}(d)+b$, where $S$ is the quantitative Sørensen index for community similarity calculated as Bray-Curtis matrices here, $d$ is the geographic distance between two samples (meters), and $z$ is the turnover rate. Where the model fitness was significant $(P<0.05)$, the $z$-value was compared between microbial communities based on the t-distribution method [44].

The effect of soil properties (Euclidean distance) or root exudate composition (Euclidean distance) on microbiome composition was tested using partial mantel analysis [41] with geographic distance as a controlled factor, and 9999 permutations for each of the sampled niches.

For variables including Shannon index and Bray-Curtis distances between two niches, the General Linear Model in Minitab (Minitab Inc. State College, PA, USA) was selected to examine the effects of niche. The regression analysis between cell wall components and microbiome Shannon index (relative to bulk soil) was performed for the root compartments including periderm, phloem and xylem, respectively. Each variable was tested and confirmed for normal distribution before running the General Linear Model.

\section{Results}

Both young and mature plants of $M$. officinalis were sampled from 24 sites in the Yellow River Delta (YRD, Fig. S1). For the mature plants, niches through the soil-root continuum including bulk soil - rhizosphere periderm - phloem - xylem (Fig. 1) were separated and analysed for the profile of bacterial community by $16 \mathrm{~S}$ rRNA gene sequencing. Due to the lack of secondary growth in young plants, the whole root was considered as the endosphere, and the microbiomes across the bulk soil - rhizosphere - endosphere continuum were evaluated.

\section{Microbial community composition and diversity through soil-plant niches}


Using amplicon sequence variants (ASVs) as operating units, microbial composition of soil-plant niches in young and mature plants was analysed by principal coordinate analysis (PCoA) based on Bray-Curtis distances. All the samples were clearly separated by niche group in the biplot (Fig. 2a) with PCoA1 and PCoA2 together explaining $46 \%$ of the variation. The ASV composition of bulk soil and rhizosphere samples overlapped substantially, and differed from the root compartments. Among the endospheric microsites, the periderm of the mature roots and endosphere of the young roots harboured similar microbiome compositions, but these were differentiated from the more interior niches, such as the phloem and xylem of the mature root. Permutational multivariate analyses of variance (PERMANOVA) showed that the effects of niche on microbiome composition was significant $\left(P<0.01, R^{2}=0.92\right)$.

In addition, the Bray-Curtis distances between adjacent niches of samples collected from the same site were calculated and compared (Fig. 2b). For mature plants, there was a greater change of ASV composition from periderm to phloem than for rhizosphere to periderm and phloem to xylem $(P<0.05)$, and the microbiome dissimilarity was the lowest between bulk soil and rhizosphere for both young and mature plants.

Analysis of microbiome taxonomic composition at the phylum level showed that there was a considerable increase of Proteobacteria (28-35\%\% vs $44-63 \%)$ and Actinobacteria (17-18\% vs $25-$ $38 \%$ ), and reduction of Acidobacteria ( $15-17 \%$ vs $1.2-3.1 \%$ ) and Bacteroidetes (5.8-6.4\% vs $2.1-4.9 \%$ ) between the soil niches (i.e. bulk soil and rhizosphere), to the root niches (i.e. periderm, phloem and xylem of mature plants, and endosphere of young plants) (Benjamini-Hochberg FDR adjusted $\mathrm{P}<0.01$, Fig. 3a).

The Shannon index of ASVs was reduced significantly ( $P<0.01$, ANOVA test) and gradually when moving from the outer microhabitats (bulk soil and rhizosphere) to the inner tissues for both mature and young plants, and the decrease on average was from 642-162 and 1336-29 for mature and the younger plants, respectively (Fig. 3b). The diversity of the rhizosphere microbiome was greater than that of the bulk soil microbiome in young plants $(P<0.05$, Fig. $3 b)$, while this difference was not significant in mature plants.

\section{Geographic location, soil properties, and root exudation of host plants all influenced the structure of root-associated microbiomes}

The distance-decay model was used to test how microbiomes changed with geographic distance between sites (Fig. 3b). We identified that the data for the outer niches (bulk soil, rhizosphere, and periderm) in mature plants fitted the model significantly, and the turnover rate ( $z$ value, related to the slope of the model) was much lower for the periderm than for the bulk soil and the rhizosphere $(P<0.01$, Table 1). However, the endophyte compositions of phloem and xylem samples were stable with increasing geographic distance, as the trend cannot be explained by the distance-decay model $(P>0.05$, Table 1 and Fig. 4a). In the rhizosphere and endosphere of young plants, the trend between microbiome composition and geographic distance fitted the distance-decay model $(P<0.01)$, and the changes of 
rhizosphere-inhabiting microbiota were more sensitive, with a greater $z$ value $(P<0.01$, Table 1 and Fig. 4b).

There was a large variation in measured soil physiochemical factors among the sampled geographic sites (Table S1). Partial mantel analysis was performed to test the effect of soil properties on microbiome assemblages at the different niches by controlling for the geographic influence (Table 1). Only the microbial community structure for bulk soil and rhizosphere of the mature plant were significantly affected by soil properties $(P<0.05$, partial mantel test, Table 1$)$.

In addition, based on the 45 compounds detected in root exudates of young and mature plants (Tables S4 and S5), there were more exudates (adjusted for root dry weight and trapping period) secreted by the young plants than by the mature plants $(\mathrm{P}<0.01$, Fig S2a). The composition of root exudates was partially separated between young and mature plants across different sites, based on the PCoA analysis (Fig $S 2 b)$. By restricting the geographic effect, partial mantel analysis revealed that root exudate compositions of the young and mature host plants were correlated with variation in microbial consortia in the rhizosphere $(P<0.01$, partial mantel test, Table 1$)$.

\section{Core microbiomes of endorhizosphere inhabitants}

For each of the studied niches, a core microbiome across the sampled sites was established, based on the most highly abundant and ubiquitous ASVs. In one niche, ASVs that appeared in at least 17 out of the 24 sampled sites (> 70\%), and ranked in the top $10 \%$ for relative abundance in every site where it was present $[45,46]$ were selected as the core ASVs. The number of core ASVs in bulk soil, rhizosphere and periderm was considerably larger than in the inner tissues ( 87 to 375 vs 6 to 18, Fig. 5). The lower number of core ASVs in phloem and xylem was possibly due to a lower total number of ASVs colonising these niches, as the proportion of unique core ASVs among total ASVs was highest in phloem and xylem, about 5.4-5.8\% compared with $0.9-1.7 \%$ for the microbiomes in bulk soil and rhizosphere, and $3.3 \%$ in the periderm (Fig S3). Interestingly, about $86 \%$ (309 out of 375) periderm core ASVs did not appear as core ASVs in other microsites, while rhizosphere microbiota of young and mature plants shared a large proportion of core ASVs.

Among core ASVs of one niche, those with $>5 \%$ relative abundance at every site where they were present were selected as the dominant ASVs. Only the niches in root tissues of mature and young plants had dominant ASVs, and totally three dominant ASVs were identified. All three dominant ASVs were present in the periderm (Fig. 6a), while the phloem and xylem harboured only one dominant ASV, ASV3 (Kineosporia) and ASVO (Ensifer), respectively, both of which were also dominant in the endosphere of young plants. ASVO (Ensifer) was the major taxon in clean nodule tissues of $M$. officinalis, with over $97 \%$ relative abundance in samples taken from different sites and from plants of different ages. We therefore conclude that ASV0 detected in this study corresponded to the symbiotic rhizobia for M. officinalis. Here, the symbiotic rhizobia appeared to be detected as ASVO which was one of the three dominant ASVs (Fig. 6a), and the only core ASV that occurred in the rhizosphere, periderm and xylem of mature plants, as well as in the endosphere of young plants (Fig. 5). 
The relative abundance of the three dominant ASVs as root-associated inhabitants was compared in mature and young plants, and the P value was adjusted using Benjamini-Hochberg FDR (Fig. 6b). In mature plants, ASVO (the symbiotic rhizobia) was highly enriched in the periderm (15\%), less abundant in xylem and rhizosphere (2.5-6.2\%), and minor in bulk soil and phloem ( $0.1-0.8 \%$, Fig. $6 \mathrm{~b})$. The relative abundance of ASV3 (Kineosporia) was greater in periderm and phloem tissues than in other niches (12$14 \%$ vs $0.02-2.4 \%$, adjusted $\mathrm{p}<0.01$, Fig. $6 \mathrm{~b}$ ). The proportion of ASV10 (Azohydromonas) was $10 \%$ in the periderm, but was quite minor in other niches (up to $1.2 \%$, Fig. $6 \mathrm{~b}$ ). In young plants, all three dominant ASVs were remarkably abundant in the endosphere $(2.7-30 \%$, adjusted $p<0.01)$, but were present in only trace amounts in the bulk soil and rhizosphere $(<0.1 \%)$.

Similarity percentage analysis (SIMPER) revealed that the three dominant ASVs were also the top contributors to the dissimilarity of microbiome composition between two neighbouring niches (Fig. 6c and Table S2-3). For example, the increased relative abundance of ASV0, ASV3 and ASV10, accounted for $15 \%$ of microbial community shift from rhizosphere to periderm for the mature plant, and the decrease of their relative abundance contributed to about $40 \%$ of microbiome dissimilarity from periderm to phloem. ASV0, the symbiotic rhizobia, was one of the top contributors to the microbiota changes between bulk soil and rhizosphere ( $1.1 \%$ contribution, mature plant), between phloem and xylem ( $2.1 \%$ contribution, mature plant), and between rhizosphere and endosphere (3.9\% contribution, young plant). Besides the three dominant ASVs, another microbe (ASV6 annotated as Allorhizobium-Neorhizobium-PararhizobiumRhizobium spp.) also affected the microbial community changes along rhizosphere-periderm-phloem, to a great extent (1.5\%-5.0\%, Table S2).

\section{Cell wall components of root compartments}

The total cell wall, cellulose, and lignin content increased from the outer to the inner root compartments (Table S4). In each of the root niches, we tested the correlation between the Shannon diversity index of the microbiome (divided by the value for the respective bulk soil in the same site for normalisation) and the content of cell wall components across sampled sites $(n=24)$. Microbial diversity was positively correlated with total cell wall and lignin content in xylem (Fig. 7b and c), but not in other root compartments.

\section{Discussion}

Melilotus officinalis exhibited a clear selection of its root microbiome and there was a preference for colonisation by certain microbial taxa through the continuum of soil, rhizosphere, periderm, phloem, and xylem zones. The periderm zone exerted a stronger selection on the microbial community than other boundaries, such as the transition from bulk soil to rhizosphere, and from phloem to xylem. The geographic distance, soil environment, root exudation activity, and root cell wall components differentially influenced microbiome composition at the various microsites.

Most previous studies of this type have used the entire sampled root as a single community $[13,14,26]$. Here, we physically dissected individual roots into separate tissues (periderm, phloem and xylem), and 
identified that the microbiome assembly in the innermost tissues (phloem and xylem) was conserved, with less variation among different geographic sites, compared with differences among the rhizosphere, rhizosphere plane and endosphere components. Both roots with primary growth (young plants) and secondary growth (mature plants) were evaluated for the development of endophyte microbial assemblies through transverse layers of root from the root surface to the central tissues. Our result provides a novel, detailed understanding of host plant - endophytic community interactions.

\section{Selection of the soil and root microbiome from the outer to inner niches}

The structure of the whole microbial community was considerably modulated from the soil niches (bulk soil and rhizosphere soil) through to the endospheric niches, indicated by the changed composition and reduced diversity. More importantly, the spatial compartments inside the root tissue (periderm, phloem and xylem) differed in the pattern and diversity of microbial colonisation to a greater extent than the differences observed between the two soil microsites (bulk soil and rhizosphere soil, Fig. 2a). Our findings demonstrated that the selective forces exerted by the root for the soil microbiome occurred not only in the rhizosphere, but also across anatomical boundaries within the root system to form a relatively distinct assemblages of microbial communities throughout the periderm, phloem and xylem. Previous studies on rice [14], Arabidopsis [13] and speargrass species [47] also found that there was a larger change of microbiome from rhizosphere to endosphere than from bulk soil to rhizosphere. Endophytic colonization of plant roots occurs in the intercellular spaces for most bacteria, possibly due to the greater quantity of carbohydrates, amino acids, and inorganic nutrients originating from apoplastic transport $[48,49]$. The penetration of microbes into internal root tissues involves both passive processes, e.g., through the cracks induced by lateral root emergence, and through active mechanisms, e.g., secreting cell-wall degrading enzymes [6]. In the present study, the increased presence of cell walls from the periderm towards the xylem (Table S4), and the appearance of Casparian strip (Fig. 1) probably contribute to the selective pressure, indicated by the selection of a less diverse microbiome (Fig. 3b). In addition, the microbial diversity of the endophyte communities in young plants were lower than those in the periderm, phloem, or xylem tissues of mature plants, possibly due to fewer lateral roots being initiated in young plants and/or shorter soil residence period of the young plant root.

The periderm must play a crucial role in controlling entry of microbes into the root, because (1) the magnitude of the shift in microbiome structure from periderm to phloem exceeded the changes across other boundaries (Fig. 2b), and (2) there was a larger number of core ASVs only present in the periderm than occurred in other niches (Fig. 5a). The importance of the periderm is that it acts as the first gate for controlling entry of the microbes from the soil niche to root tissue. Other endospheric boundaries separate two compartments within the root. The effect of the rhizoplane (part of the periderm in our study) on filtering the microbiome has been defined as a 'critical gating role' in previous studies $[14,19]$. Biofilm formation and adhesion ability during the plant-microbe interaction occurs on the root surface such as the periderm, which could lead to a more pronounced selection of microbial communities [11]. 


\section{The effects of geographic location, soil properties, root exudation, and cell wall content on shaping the microbiome of root niches}

For the niches in close proximity to soils including bulk soil, rhizosphere, periderm (mature plants), and endosphere (young plants), their microbiome assembly was driven by stochastic processes (geographic factors) and deterministic processes (edaphic factors and root activity). However, the colonization and persistence of endophytes in the interior tissues (phloem and xylem) of mature plants were more conserved and stable across environments, and their diversity was influenced by the amount of cell-wall components formed in different plants.

A distance-decay model was used to describe microbial community similarity in relation to increased geographic distance [50]. Microbiomes inhabiting bulk soil and rhizosphere were more sensitive to geographic change than those of the periderm and endosphere (young plants), indicated by the greater turnover rate in the distance-decay model (Table 1 and Fig. 4), possibly because the microbiome composition in the periderm (mature plants) and the endosphere (young plants) is subject to not only the microbial reservoir of the background soil, which varies across geographic locations, but also to recruitment by the host plant, involving features such as the cell wall (about $37-45 \%$ of the total tissue). Moreover, soil properties were only associated with microbiome structure in the two soil-related niches (bulk soil and rhizosphere soil) of the mature plants, but not for the young rhizosphere, possibly because the soil residence period, which has been regarded as the key factor forming the rhizobiome structure for perennial plants [51], was too short for the young plants to modulate their rhizosphere microbiome, compared with the mature plants.

The composition of root exudates influenced the rhizosphere-inhabiting microbiota in both mature and young plants, while the variation in root exudation activity did not show any exceptional trends with geographic and soil factors. The rhizosphere is rich with diverse metabolites secreted from the root, and this process is controlled by plant genetics, i.e., genes related to synthesis of specific root exudates [52, 53], as well as the heterogeneous growing environments, e.g., soil, climate, and neighbouring plant species [54]. Our findings here showed that variation in root exudation activity did not affect the structure of the endophyte community, which was more stable across environments than the rhizosphere microbiome.

The apoplast mainly comprises plant cell walls, and bacteria commonly grow in this environment, attached to plant cell walls [55]. Our analysis of chemical cell wall constituents also showed a large variation between the periderm, phloem and xylem, with total cell wall and lignin content increasing from the outer to inner tissues (Table S4). Additionally, the microbiome diversity decreased from phloem to xylem (Fig. 3b) while the total cell wall and lignin content increased (Table S4), so cell walls were likely the structural barriers leading to the selection of certain endophyte species. Lignin is not metabolically active, and its deposition has been regarded as an important mechanism contributing to structural root 
defences to control microbes [56]. The woody appearance of mature root systems and the increased lignification of cell walls from secondary growth leads to a homogeneous root endophytic community across different plant species [8]. For example, around $40 \%$ of bacterial endophytes colonising Arabidopsis also inhabited wooden splinters of two tree species incubated in the same soils [13]. Here we demonstrated that increased cell wall and lignin content in the xylem was associated with higher diversity of xylem-inhabiting endophytes (Fig. 7), possibly because cell wall components can act as growth substrates for certain bacteria that can produce cell-wall degrading enzymes.

\section{Selection for specific microbes from the outer to inner niches}

The composition of phylum groups differed between soil and root niches, while the variation within the root i.e., among periderm, phloem and xylem tissues, was minor (Fig. 3a). Compared with soil niches, root tissues harboured a larger proportion of Proteobacteria and Actinobacteria, but less Acidobacteria, which is in line with observations for Arabidopsis [13] and rice [14]. In addition, three microbes that were ubiquitous across sampled sites and highly abundant in specific root niches, were identified as Proteobacteria or Actinobacteria, including ASV0 (Ensifer spp., Proteobacteria), ASV3 (Kineosporia spp., Actinobacteria), and ASV10, (Azohydromonas spp., Proteobacteria). These three microbes also act as the top contributors to the shift of microbiome composition between the neighbouring niches, e.g., rhizosphere-periderm, periderm-phloem, phloem-xylem, and rhizosphere-endosphere (young plants).

As an important microbe for legumes, ASVO (Ensifer spp., Proteobacteria) is the symbiotic nitrogen fixing partner for M. officinalis, and was highly abundant in the periderm (mature plants) and endosphere (young plants Fig. 6a). This was likely related to the nodulation process: formation of the nodule primordium is usually facilitated through activation of cell division in the epidermal, cortical, and pericycle zones [57], that were sampled as the periderm zone (mature plant) and endosphere (young plant) in our study. Additionally, besides the periderm and endosphere, the mean relative abundance of $M$. officinalis symbiotic rhizobia was second highest in the xylem, but quite minor in the phloem (located between periderm and xylem). Interestingly, our results are in line with a previous study [58] that during nodule formation there was a nodule-inducing factor present in the protoxylem, and an inhibitor in the protophloem, although the conclusion was based on a model legume plant, Medicago truncatula, with a short lifespan and only primary growth.

Another Kineosporia (ASV3) was enriched in the periderm and phloem of mature plants, and the young plant's endosphere (Fig. 6b). As a non-streptomycete actinobacteria, Kineosporia has been found to inhabit the tissues of plant roots and leaves [59,60], which is possibly associated with its ability to utilise complex substrates [61], such as cell wall components in the present study. Network analysis on Arabidopsis root endophytes showed that Kineosporia was one of the five keystone taxa determining negative interkingdom connections between bacterial and fungal microbiota [59].

Furthermore, the soil-attached root tissues (periderm of the mature plant and endosphere of the young plant) were colonised by Azohydromonas bacteria (ASV10) with a larger proportion than other niches 
(Fig. 6c). Azohydromonas are free-living nitrogen fixers (containing nifH genes), and have been widely observed in the rhizospheres and endospheres of leguminous and non-leguminous plants [62, 63]. From previous findings, Azohydromonas bacteria appeared to co-exist with the symbiotic rhizobia of the legumes, and were dominant in nodule surface or nodule tissues $[64,65]$. Likewise, our results corroborated previous work from Brown et al [64] and Tkacz et al [65], showing that those niches that were enriched for symbiotic rhizobia also harboured more Azohydromonas bacteria.

\section{Conclusions}

Overall, $M$. officinalis exerted significant selection on components of the plant-associated microbiome, when grown in field soils, such that clear segregations in microbial communities existed among the different compartments of the soil-plant root system including bulk soil, rhizosphere, periderm, phloem and xylem. The periderm zone was an important selective barrier in controlling the composition of the endophyte community assemblages. Variation in microbiomes for bulk soil and the rhizosphere was associated with geographic distance and soil properties of sampling sites, while root exudation activity of the host plant was more important in determining rhizosphere microbiomes. Geographically distinct plant populations nevertheless formed similar endophytic communities in the phloem and xylem. A greater focus on the conserved endophyte microbial community may help to identify important plant functions that modify plant root disease, nutrient accumulation, abiotic stress tolerance, and ultimately, improve plant productivity. Understanding the nature of the selection of microbes through different root anatomical boundaries may be advantageous to the development of specific beneficial microbial inoculants.

\section{Abbreviations}

YRD: Yellow River Delta

ASV: amplicon sequence variant

GC: gas chromatography

PCoA: principal coordinate analyses

PERMANOVA: permutational multivariate analyses of variance

NDF: neutral detergent fibre

ADF: acid detergent fibre

SIMPER: Similarity percentage analysis

STAMP: Statistical Analysis of Metagenomic Profiles 


\section{Declarations}

\section{Ethics approval and consent to participate}

Not applicable

\section{Consent for publication}

Not applicable

\section{Availability of data and material}

The raw sequenced data from the Illumina MiSeq platform are available at National Center for Biotechnology Information (NCBI), Sequence Read Archive (https://www.ncbi.nlm.nih.gov/sra) with the project ID: PRJNA603423. The datasets supporting the conclusions of this article are included within the article and its additional files.

\section{Competing interests}

The authors declare that they have no competing interests

\section{Funding}

This work was supported by the International Technology Cooperation Project from Shandong Academy of Sciences (project ID: 2019GHZD11), the Major Technological Innovation Project in Agricultural Applications from Shandong Provincial Department of Agriculture, the Youth Foundation of Shandong Natural Science Foundation of China (project ID: ZR2019BC076), Collaborative Innovation Fund of the Shandong Academy of Sciences \& Local Government (project ID: 2019-CXY5) and the fund from Shandong Provincial Administration of Foreign Experts Affairs. The support of the Australian Research Council (IH140100013), the Grains Research and Development Corporation, the Department of Trade, Tourism and Investment of the South Australian Government, and the University of Adelaide in this work is acknowledged.

\section{Authors' contributions}

YZ, WY, JL and MD designed the study, conducted all the experiments, and interpreted all of the data. YZ and MD wrote the article. ZZ conducted the DNA extraction and qPCR analysis and interpreted the results. $\mathrm{HL}$ and RT analysed the soils, and prepared the plant and soil samples for sequencing. PY and ST undertook the root exudation analysis and interpreted the results. MR and HY performed the field trials and analysed the results. All authors contributed to revising the manuscript, and approved the final submission.

\section{Acknowledgements}

We acknowledge Professor Petra Marschner for her assistance with commenting on the manuscript. 


\section{References}

1. Berendsen RL, Pieterse CM, Bakker PA: The rhizosphere microbiome and plant health. Trends Plant Sci. 2012; 17:478-486.

2. Mendes R, Kruijt M, de Bruijn I, Dekkers E, van der Voort M, Schneider JHM, Piceno YM, DeSantis TZ, Andersen GL, Bakker PAHM, Raaijmakers JM: Deciphering the rhizosphere microbiome for diseasesuppressive bacteria. Science. 2011; 332:1097-1100.

3. Zhang H, Sun Y, Xie X, Kim MS, Dowd SE, Paré PW: A soil bacterium regulates plant acquisition of iron via deficiency - inducible mechanisms. Plant J. 2009; 58:568-577.

4. Sturz A, Nowak J: Endophytic communities of rhizobacteria and the strategies required to create yield enhancing associations with crops. Appl Soil Ecol. 2000; 15:183-190.

5. Zhou Y, Coventry DR, Gupta VV, Fuentes D, Merchant A, Kaiser BN, Li J, Wei Y, Liu H, Wang Y: The preceding root system drives the composition and function of the rhizosphere microbiome. Genome Biol. 2020; 21:1-19.

6. Compant S, Clément $C$, Sessitsch A: Plant growth-promoting bacteria in the rhizo-and endosphere of plants: their role, colonization, mechanisms involved and prospects for utilization. Soil Biol Biochem. 2010; 42:669-678.

7. Chanway CP, Shishido M, Nairn J, Jungwirth S, Markham J, Xiao G, Holl FB: Endophytic colonization and field responses of hybrid spruce seedlings after inoculation with plant growth-promoting rhizobacteria. For Ecol Manag. 2000; 133:81-88.

8. Bulgarelli D, Schlaeppi K, Spaepen S, Van Themaat EVL, Schulze-Lefert P: Structure and functions of the bacterial microbiota of plants. Annu Rev Plant Biol. 2013; 64:807-838.

9. Fitzpatrick CR, Copeland J, Wang PW, Guttman DS, Kotanen PM, Johnson MTJ: Assembly and ecological function of the root microbiome across angiosperm plant species. Proc Natl Acad Sci U S A. $2018 ; 115: E 1157-E 1165$.

10. Naylor D, DeGraaf S, Purdom E, Coleman-Derr D: Drought and host selection influence bacterial community dynamics in the grass root microbiome. ISME J. 2017; 11:2691-2704.

11. Reinhold-Hurek B, Bünger W, Burbano CS, Sabale M, Hurek T: Roots shaping their microbiome: global hotspots for microbial activity. Annu Rev Phytopathol. 2015; 53:403-424.

12. Bulgarelli D, Garrido-Oter R, Muench PC, Weiman A, Droege J, Pan Y, McHardy AC, Schulze-Lefert P: Structure and function of the bacterial root microbiota in wild and domesticated barley. Cell Host Microbe. 2015; 17:392-403.

13. Bulgarelli D, Rott M, Schlaeppi K, van Themaat EVL, Ahmadinejad N, Assenza F, Rauf P, Huettel B, Reinhardt R, Schmelzer E, et al: Revealing structure and assembly cues for Arabidopsis rootinhabiting bacterial microbiota. Nature. 2012; 488:91-95.

14. Edwards J, Johnson C, Santos-Medellin C, Lurie E, Podishetty NK, Bhatnagar S, Eisen JA, Sundaresan $\mathrm{V}$ : Structure, variation, and assembly of the root-associated microbiomes of rice. Proc Natl Acad Sci U S A. 2015; 112:E911-E920. 
15. Sharaf H, Rodrigues RR, Moon J, Zhang B, Mills K, Williams MA: Unprecedented bacterial community richness in soybean nodules vary with cultivar and water status. Microbiome. 2019; 7.

16. Sun H, Kang B, Chai Z, Sun H, Du H, Gao J, Feng Q, Zhang C, Cao Q, Guo L: Characterization of rootassociated microbiota in medicinal plants Astragalus membranaceus and Astragalus mongholicus. Ann. Microbiol. 2017; 67:587-599.

17. Lopez-Fernandez S, Compant S, Vrhovsek U, Bianchedi PL, Sessitsch A, Pertot I, Campisano A: Grapevine colonization by endophytic bacteria shifts secondary metabolism and suggests activation of defense pathways. Plant Soil. 2016; 405:155-175.

18. Compant S, Reiter B, Sessitsch A, Nowak J, Clément C, Barka EA: Endophytic colonization of Vitis vinifera L. by plant growth-promoting bacterium Burkholderia sp. strain PsJN. Appl Environ Microbiol. 2005; 71:1685-1693.

19. Liu H, Carvalhais LC, Crawford M, Singh E, Dennis PG, Pieterse CMJ, Schenk PM: Inner plant values: Diversity, colonization and benefits from endophytic bacteria. Front Microbiol. 2017; 8:2552.

20. Pausch J, Kuzyakov Y: Carbon input by roots into the soil: quantification of rhizodeposition from root to ecosystem scale. Glob Chang Biol. 2018; 24:1-12.

21. De la Fuente Canto C, Simonin M, King E, Moulin L, Bennett MJ, Castrillo G, Laplaze L: An extended root phenotype: the rhizosphere, its formation and impacts on plant fitness. Plant J. 2020; 103:951964.

22. Edwards JA, Santos-Medellín CM, Liechty ZS, Nguyen B, Lurie E, Eason S, Phillips G, Sundaresan V: Compositional shifts in root-associated bacterial and archaeal microbiota track the plant life cycle in field-grown rice. PLoS Biol. 2018; 16:e2003862.

23. Xu L, Naylor D, Dong ZB, Simmons T, Pierroz G, Hixson KK, Kim YM, Zink EM, Engbrecht KM, Wang Y, et al: Drought delays development of the sorghum root microbiome and enriches for monoderm bacteria. Proc Natl Acad Sci U S A. 2018; 115:E4284-E4293.

24. Chaparro JM, Badri DV, Vivanco JM: Rhizosphere microbiome assemblage is affected by plant development. ISME J. 2014; 8:790-803.

25. Udvardi M, Poole PS: Transport and metabolism in legume-rhizobia symbioses. Annu Rev Plant Biol. 2013; 64:781-805.

26. Xiao X, Chen W, Zong L, Yang J, Jiao S, Lin Y, Wang E, Wei G: Two cultivated legume plants reveal the enrichment process of the microbiome in the rhizocompartments. Mol. Ecol. 2017; 26:1641-1651.

27. Mao W, Kang S, Wan Y, Sun Y, Li X, Wang Y: Yellow river sediment as a soil amendment for amelioration of saline land in the Yellow river delta. Land Degrad Dev. 2016; 27:1595-1602.

28. Guan B, Chen M, Elsey-Quirk T, Yang S, Shang W, Li Y, Tian X, Han G: Soil seed bank and vegetation differences following channel diversion in the Yellow River Delta. Sci Total Environ. 2019; 693:133600.

29. Zhang Y-m, Ma H-I, Calderón-Urrea A, Tian C-x, Bai X-m, Wei J-m: Anatomical changes to protect organelle integrity account for tolerance to alkali and salt stresses in Melilotus officinalis. Plant Soil. 2016; 406:327-340. 
30. Thijs S, Op De Beeck M, Beckers B, Truyens S, Stevens V, Van Hamme JD, Weyens N, Vangronsveld J: Comparative evaluation of four bacteria-specific primer pairs for $16 \mathrm{~S}$ rRNA gene surveys. Front Microbiol. 2017; 8:494-494.

31. Bolyen E, Rideout JR, Dillon MR, Bokulich NA, Abnet CC, Al-Ghalith GA, Alexander H, Alm EJ, Arumugam M, Asnicar F: Reproducible, interactive, scalable and extensible microbiome data science using QIIME 2. Nature Biotechnol. 2019; 37:852-857.

32. Callahan BJ, McMurdie PJ, Rosen MJ, Han AW, Johnson AJA, Holmes SP: DADA2: high-resolution sample inference from Illumina amplicon data. Nat Methods. 2016; 13:581-583.

33. Quast C, Pruesse E, Yilmaz P, Gerken J, Schweer T, Yarza P, Peplies J, Glöckner FO: The SILVA ribosomal RNA gene database project: improved data processing and web-based tools. Nucleic Acids Res. 2012; 41:D590-D596.

34. Brosnan JT, Ebdon J, Dest W: Characteristics in diverse wear tolerant genotypes of Kentucky bluegrass. Crop Sci. 2005; 45:1917-1926.

35. Rayment GE, Lyons DJ: Soil chemical methods: Australasia. CSIRO publishing; 2011.

36. Aulakh M, Wassmann R, Bueno C, Kreuzwieser J, Rennenberg H: Characterization of root exudates at different growth stages of ten rice (Oryza sativa L.) cultivars. Plant Biol. 2001; 3:139-148.

37. Dietz S, Herz K, Döll S, Haider S, Jandt U, Bruelheide H, Scheel D: Semi-polar root exudates in natural grassland communities. Ecol Evol. 2019; 9:5526-5541.

38. Conselvan GB, Fuentes D, Merchant A, Peggion C, Francioso O, Carletti P: Effects of humic substances and indole-3-acetic acid on Arabidopsis sugar and amino acid metabolic profile. Plant Soil. 2018; 426:1-16.

39. R Core Team: R: A language and environment for statistical computing. 2013.

40. Robinson MD, Oshlack A: A scaling normalization method for differential expression analysis of RNA-seq data. Genome Bio. 2010; 11:R25.

41. Oksanen J, Kindt R, Legendre P, O'Hara B, Stevens MHH, Oksanen MJ, Suggests M: The vegan package. Community ecology package 2007, 10:631-637.

42. Hsieh T, Ma K, Chao A: iNEXT: an R package for rarefaction and extrapolation of species diversity (Hill numbers). Methods Ecol Evol. 2016; 7:1451-1456.

43. Parks DH, Tyson GW, Hugenholtz P, Beiko RG: STAMP: statistical analysis of taxonomic and functional profiles. Bioinformatics. 2014; 30:3123-3124.

44. Zhang K, Adams JM, Shi Y, Yang T, Sun R, He D, Ni Y, Chu H: Environment and geographic distance differ in relative importance for determining fungal community of rhizosphere and bulk soil. Environ Microbiol. 2017; 19:3649-3659.

45. Delgado-Baquerizo M, Oliverio AM, Brewer TE, Benavent-González A, Eldridge DJ, Bardgett RD, Maestre FT, Singh BK, Fierer N: A global atlas of the dominant bacteria found in soil. Science. 2018; 359:320-325. 
46. Jiao S, Xu Y, Zhang J, Hao X, Lu Y: Core microbiota in agricultural soils and their potential associations with nutrient cycling. Msystems. 2019; 4:e00313-00318.

47. Marasco R, Mosqueira MJ, Fusi M, Ramond JB, Merlino G, Booth JM, Maggs-Kolling G, Cowan DA, Daffonchio D: Rhizosheath microbial community assembly of sympatric desert speargrasses is independent of the plant host. Microbiome. 2018; 6:215.

48. Hardoim PR, van Overbeek LS, Berg G, Pirttilä AM, Compant S, Campisano A, Döring M, Sessitsch A: The hidden world within plants: ecological and evolutionary considerations for defining functioning of microbial endophytes. Microbiol Mol Biol Rev. 2015; 79:293-320.

49. Kandel SL, Joubert PM, Doty SL: Bacterial endophyte colonization and distribution within plants. Microorganisms. 2017; 5:77.

50. Hu J, Zhou Y, Chen K, Li J, Wei Y, Wang Y, Wu Y, Ryder MH, Yang H, Denton MD: Large-scale Trichoderma diversity was associated with ecosystem, climate and geographic location. Environ Microbiol. 2020; 22:1011-1024.

51. Dombrowski N, Schlaeppi K, Agler MT, Hacquard S, Kemen E, Garrido-Oter R, Wunder J, Coupland G, Schulze-Lefert P: Root microbiota dynamics of perennial Arabis alpina are dependent on soil residence time but independent of flowering time. ISME J. 2017; 11:43-55.

52. Kudjordjie EN, Sapkota R, Steffensen SK, Fomsgaard IS, Nicolaisen M: Maize synthesized benzoxazinoids affect the host associated microbiome. Microbiome. 2019; 7:59.

53. Lebeis SL, Paredes SH, Lundberg DS, Breakfield N, Gehring J, McDonald M, Malfatti S, Del Rio TG, Jones CD, Tringe SG: Salicylic acid modulates colonization of the root microbiome by specific bacterial taxa. Science. 2015; 349:860-864.

54. Badri DV, Vivanco JM: Regulation and function of root exudates. Plant Cell Environ. 2009; 32:666681.

55. Du Y, Stegmann M, Misas Villamil JC: The apoplast as battleground for plant-microbe interactions. New Phytol. 2016; 209:34-38.

56. Pascale A, Proietti S, Pantelides IS, Stringlis IA: Modulation of the root microbiome by plant molecules: the basis for targeted disease suppression and plant growth promotion. Front. Plant Sci..2020; 10:1741.

57. Desbrosses Guilhem J, Stougaard J: Root nodulation: a paradigm for how plant-microbe symbiosis influences host developmental pathways. Cell Host Microbe. 2011; 10:348-358.

58. Gage DJ: Infection and invasion of roots by symbiotic, nitrogen-fixing rhizobia during nodulation of temperate legumes. Microbiol Mol Biol Rev. 2004; 68:280-300.

59. Durán P, Thiergart T, Garrido-Oter R, Agler M, Kemen E, Schulze-Lefert P, Hacquard S: Microbial interkingdom interactions in roots promote Arabidopsis survival. Cell. 2018; 175:973-983.

60. Purahong W, Wubet T, Lentendu G, Schloter M, Pecyna MJ, Kapturska D, Hofrichter M, Krüger D, Buscot F: Life in leaf litter: novel insights into community dynamics of bacteria and fungi during litter decomposition. Mol Ecol. 2016; 25:4059-4074. 
61. Dinesh R, Srinivasan V, TE S, Anandaraj M, Srambikkal H: Endophytic actinobacteria: diversity, secondary metabolism and mechanisms to unsilence biosynthetic gene clusters. Crit Rev Microbiol. 2017; 43:546-566.

62. Rodrigues Coelho MR, De Vos M, Carneiro NP, Marriel IE, Paiva E, Seldin L: Diversity of nifH gene pools in the rhizosphere of two cultivars of sorghum (Sorghum bicolor) treated with contrasting levels of nitrogen fertilizer. FEMS Microbiol Lett. 2008; 279:15-22.

63. Yang C, Hamel C, Vujanovic V, Gan Y: Nontarget effects of foliar fungicide application on the rhizosphere: diversity of nifH gene and nodulation in chickpea field. J Appl Microbiol. 2012; 112:966974.

64. Brown SP, Grillo MA, Podowski JC, Heath KD: Soil origin and plant genotype structure distinct microbiome compartments in the model legume Medicago truncatula. Microbiome. 2020; 8:1-17.

65. Tkacz A, Bestion E, Bo Z, Hortala M, Poole PS: Influence of plant fraction, soil, and plant species on microbiota: a multikingdom comparison. MBio. 2020; 11:e02785-02719.

66. Parker AJ, Haskins EF, Deyrup-Olsen I: Toluidine blue: a simple, effective stain for plant tissues. Am Biol Teach. 1982; 44:487-489.

\section{Table}

Table 1. The effects of geographic distance, soil properties, and root exudation on the microbiome composition at root-associated niches of Melilotus officinalis mature and young plants.

A distance-decay model was used to test the relationship between microbiome similarity and geographic distance. The $z$ value is the turnover rate in the model, indicating the sensitivity of microbiome changes with increased geographic distance. A partial mantel test was performed to examine the effect of soil or root exudation by controlling for geographic distance, and the $r$ value is presented. ns: not significant, *: significant at $\mathrm{P}<0.05$, and $* *$ : significant at $\mathrm{P}<0.01$ 


\begin{tabular}{|c|c|c|c|c|c|}
\hline & \multicolumn{3}{|c|}{ Distance-decay Model } & \multicolumn{2}{|l|}{ Partial Mantel Tests } \\
\hline & z-value & $P$ value & $\mathrm{R}^{2}$ & $\begin{array}{l}\text { The effect of } \\
\text { soil properties, } \\
\text { controlling for } \\
\text { geographic distance }\end{array}$ & $\begin{array}{l}\text { The effect of } \\
\text { root exudation, } \\
\text { controlling for } \\
\text { geographic distance }\end{array}$ \\
\hline \multicolumn{6}{|c|}{ Microbiome in the mature plant: } \\
\hline Bulk soil & $0.133 a$ & $<0.01$ & 0.59 & $0.17 *$ & - \\
\hline Rhizosphere & $0.131 a$ & $<0.01$ & 0.61 & $0.44 \star \star$ & $0.43^{\star \star}$ \\
\hline Periderm & $0.0181 b$ & $<0.01$ & 0.11 & $0.11 \mathrm{~ns}$ & $0.13 n s$ \\
\hline Phloem & 0.00475 & 0.118 & 0.09 & $0.03 n s$ & $0.06 \mathrm{~ns}$ \\
\hline Xylem & 0.00590 & 0.151 & 0.08 & $0.01 \mathrm{~ns}$ & $0.06 \mathrm{~ns}$ \\
\hline \multicolumn{6}{|c|}{ Microbiome in the young plant: } \\
\hline Bulk soil & $0.133 \mathrm{~A}$ & $<0.01$ & 0.59 & $0.17^{\star}$ & - \\
\hline Rhizosphere & $0.0772 B$ & $<0.01$ & 0.52 & $0.13 n s$ & $0.19 \star \star$ \\
\hline Endosphere & $0.0581 \mathrm{C}$ & $<0.01$ & 0.23 & $0.12 \mathrm{~ns}$ & $0.02 \mathrm{~ns}$ \\
\hline \multicolumn{6}{|c|}{ Root exudate composition: } \\
\hline Young plants & - & - & -- & $0.10 \mathrm{~ns}$ & - \\
\hline Mature plants & - & - & - & $0.01 \mathrm{~ns}$ & - \\
\hline
\end{tabular}

\section{Figures}


(a) Mature plant

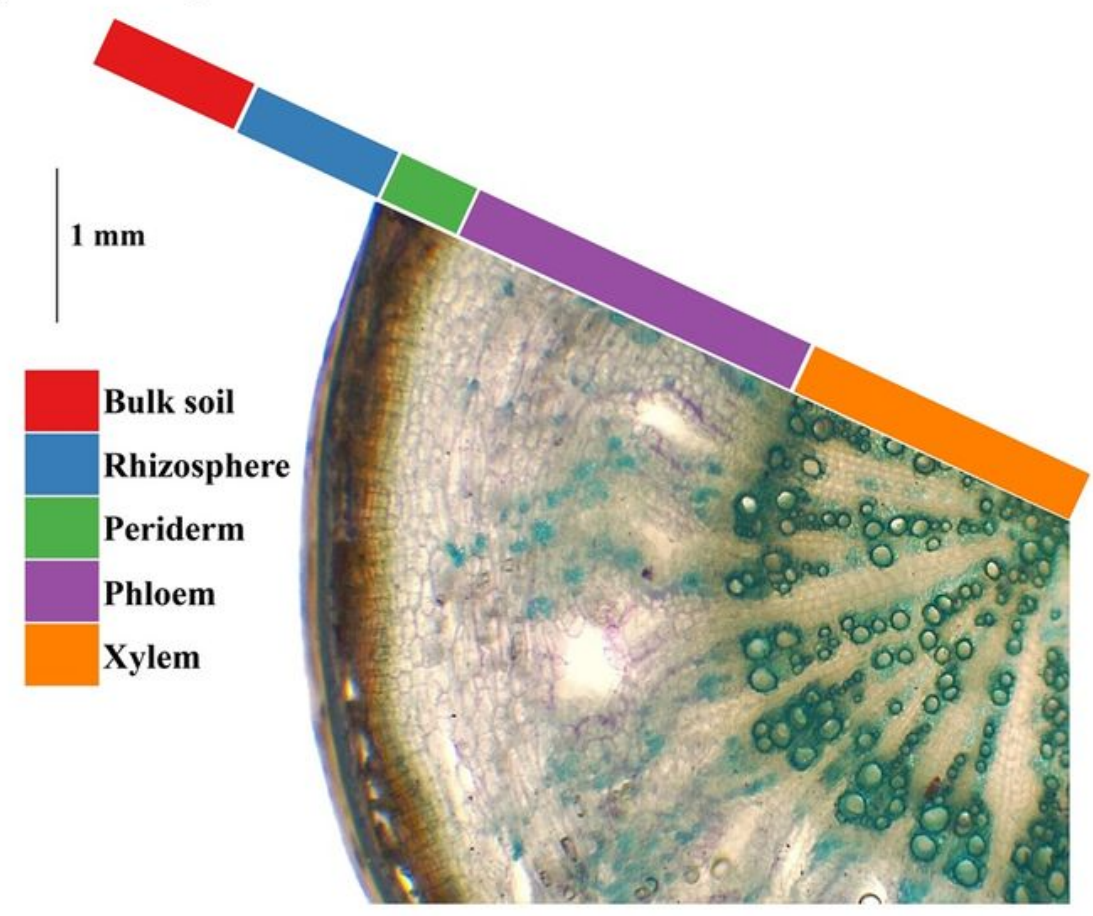

(b) Young plant

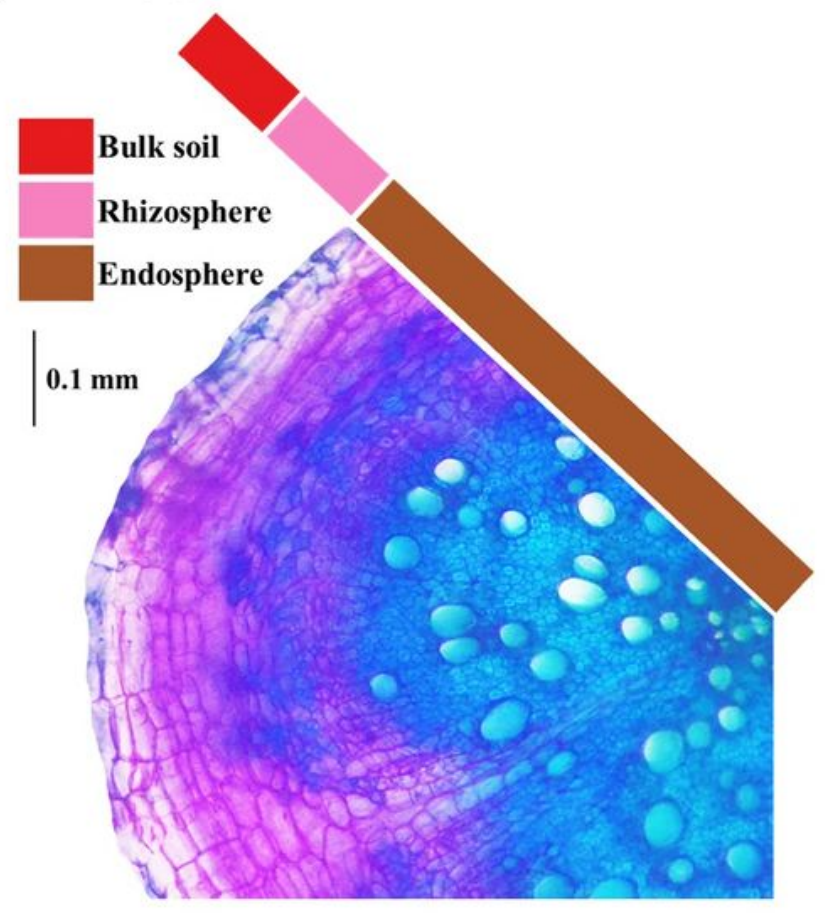

\section{Figure 1}

Melilotus officinalis root cross section showing the niches sampled in the (a) mature and (b) young plants. Samples were stained by Toluidine Blue. Coloration indicates cell types and tissue structure based on Parker et al [66]. Green: lignified structures; Unstained: starch; Red-Purple: parenchyma and collenchyma; Blue: sclerenchyma. 


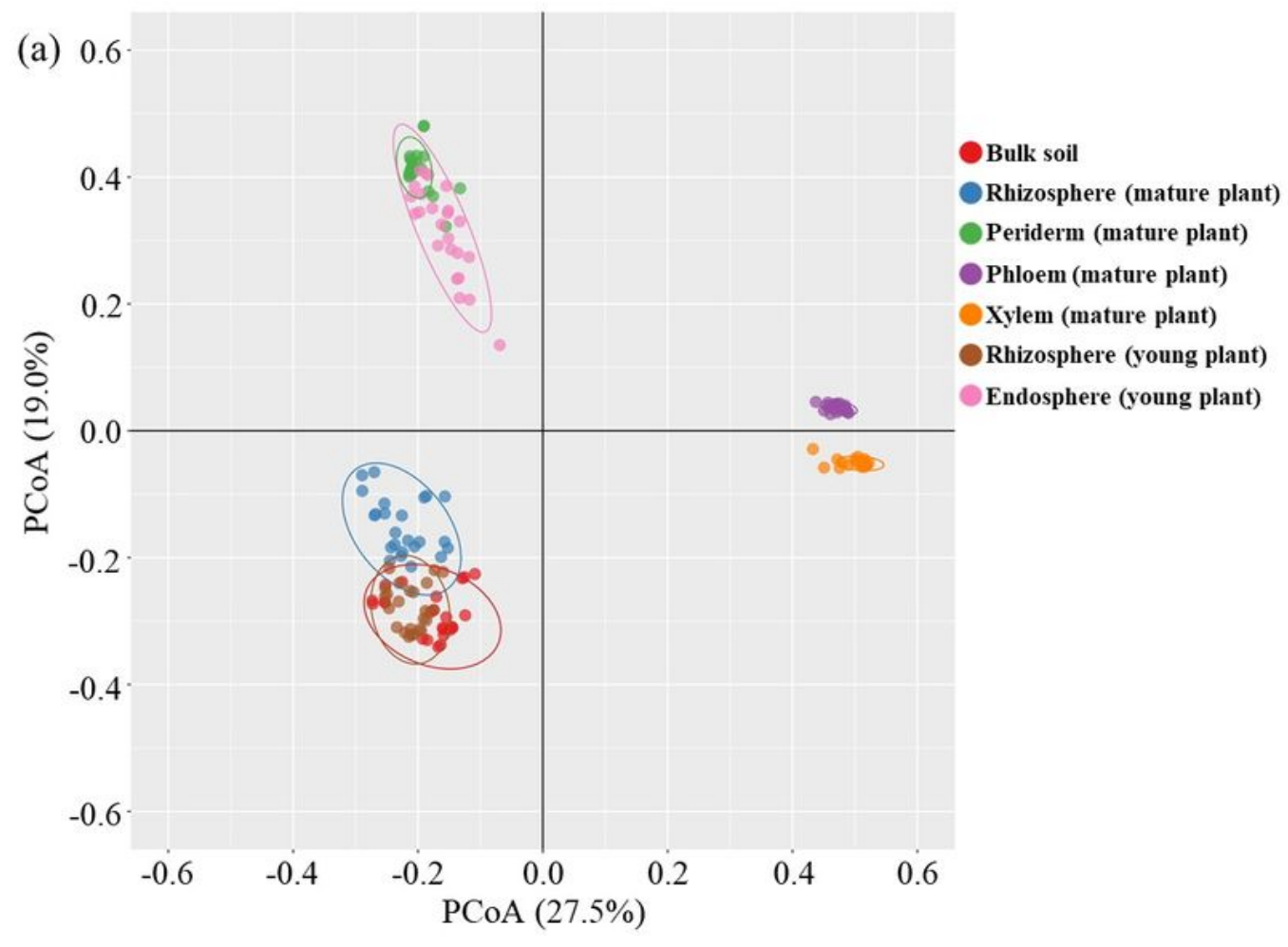

(b) 1.00 -

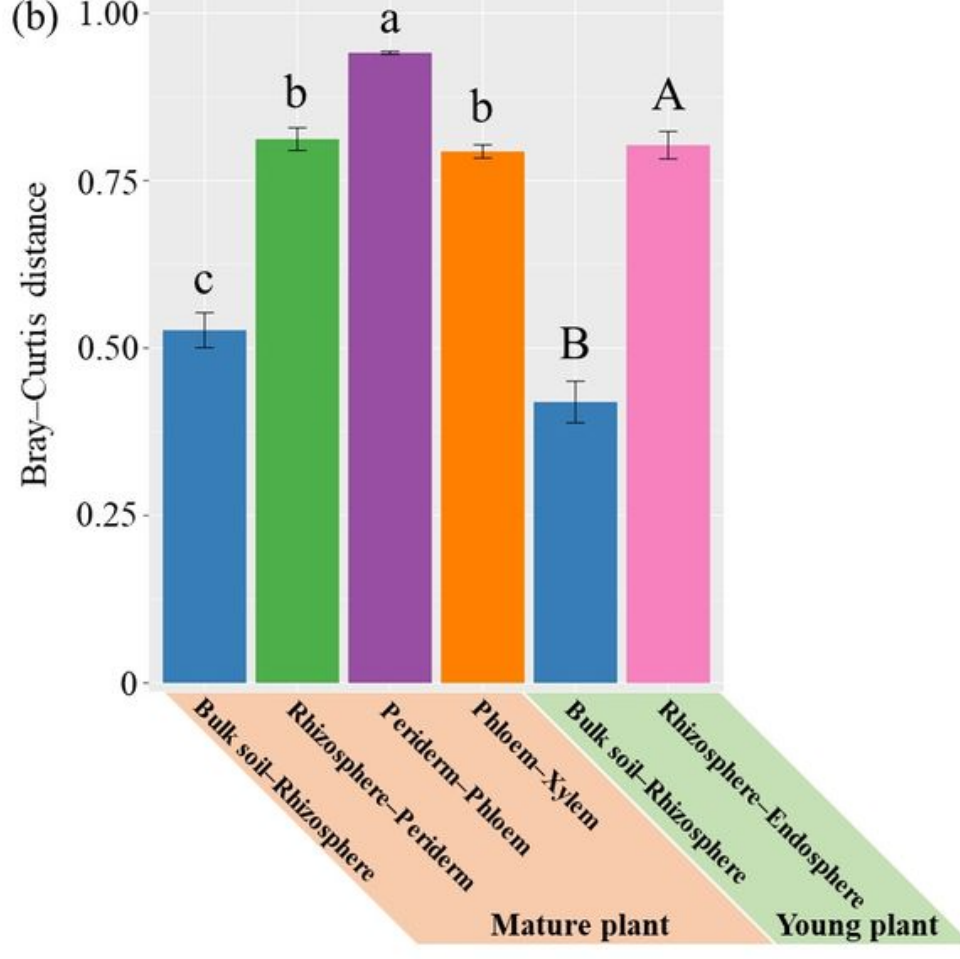

\section{Figure 2}

Microbial composition of root-associated niches of Melilotus officinalis collected from 24 sites in the Yellow River Delta. (a) Biplots based on principal coordinate analysis (PCoA) using Bray-Curtis distances. (b) The Bray-Curtis distance between two neighbouring niches across different sites. Error bars indicate the standard error. The same lowercase / uppercase letters indicate no significant differences $(P<0.05)$ between niches within mature / young plants based on Tukey HSD post-hoc pairwise comparison tests. 

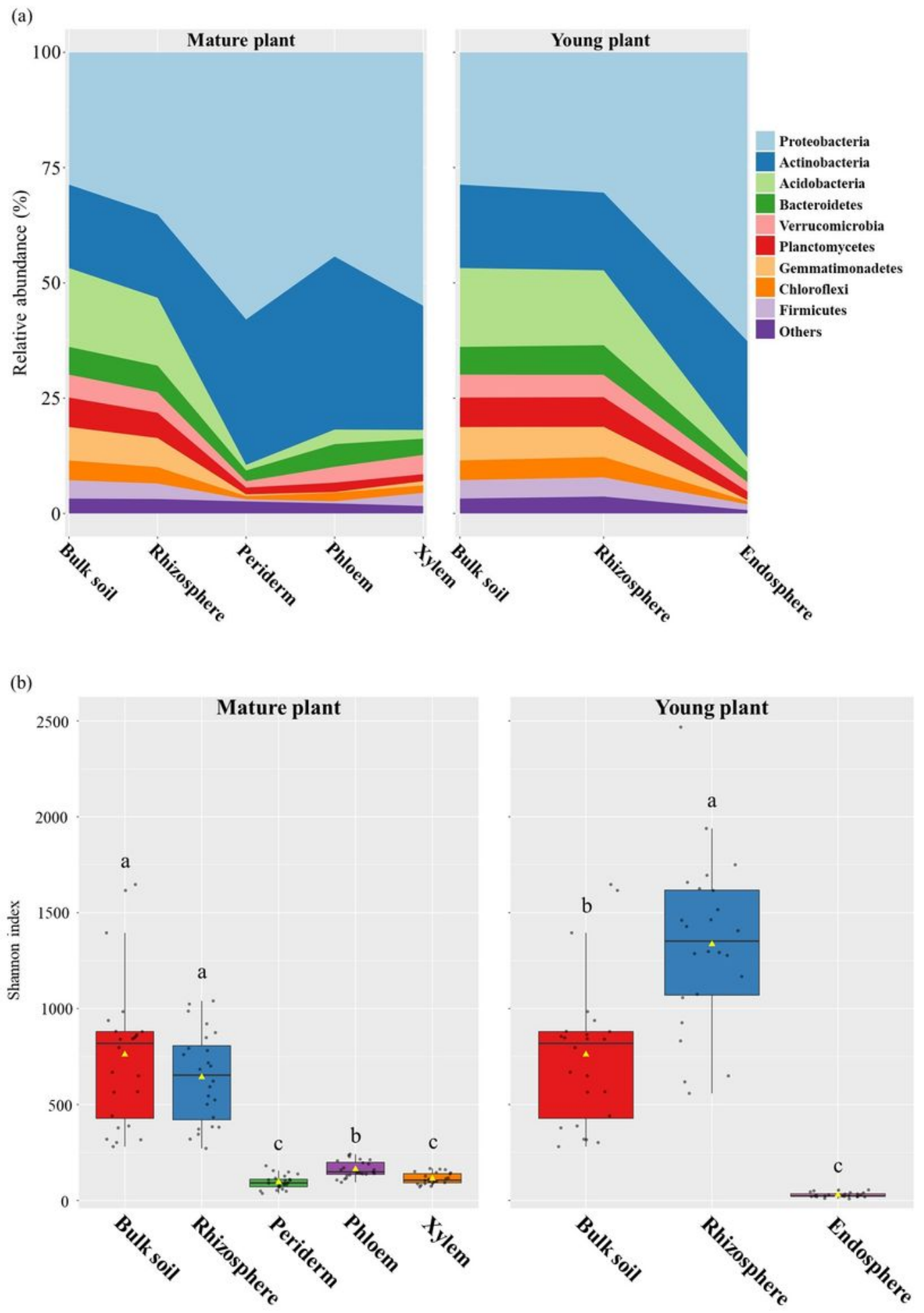

\section{Figure 3}

Composition and diversity of microbiomes from bulk soil, rhizosphere, periderm, phloem and xylem of Melilotus officinalis. (a) Relative abundance of main phylum groups and (b) Shannon index indicating bacterial community composition and diversity, respectively. Mature plants and young plants (where the endosphere was sampled as the whole root compartments) were analysed. The values for individual samples are presented in the boxplot. The yellow triangle is the mean, and the box and central line 
represent first quartiles, medians, and third quartiles, respectively. The same lowercase / uppercase letters indicate no significant differences $(P<0.05)$ between niches within mature / young plants based on Tukey HSD post-hoc pairwise comparison testing.

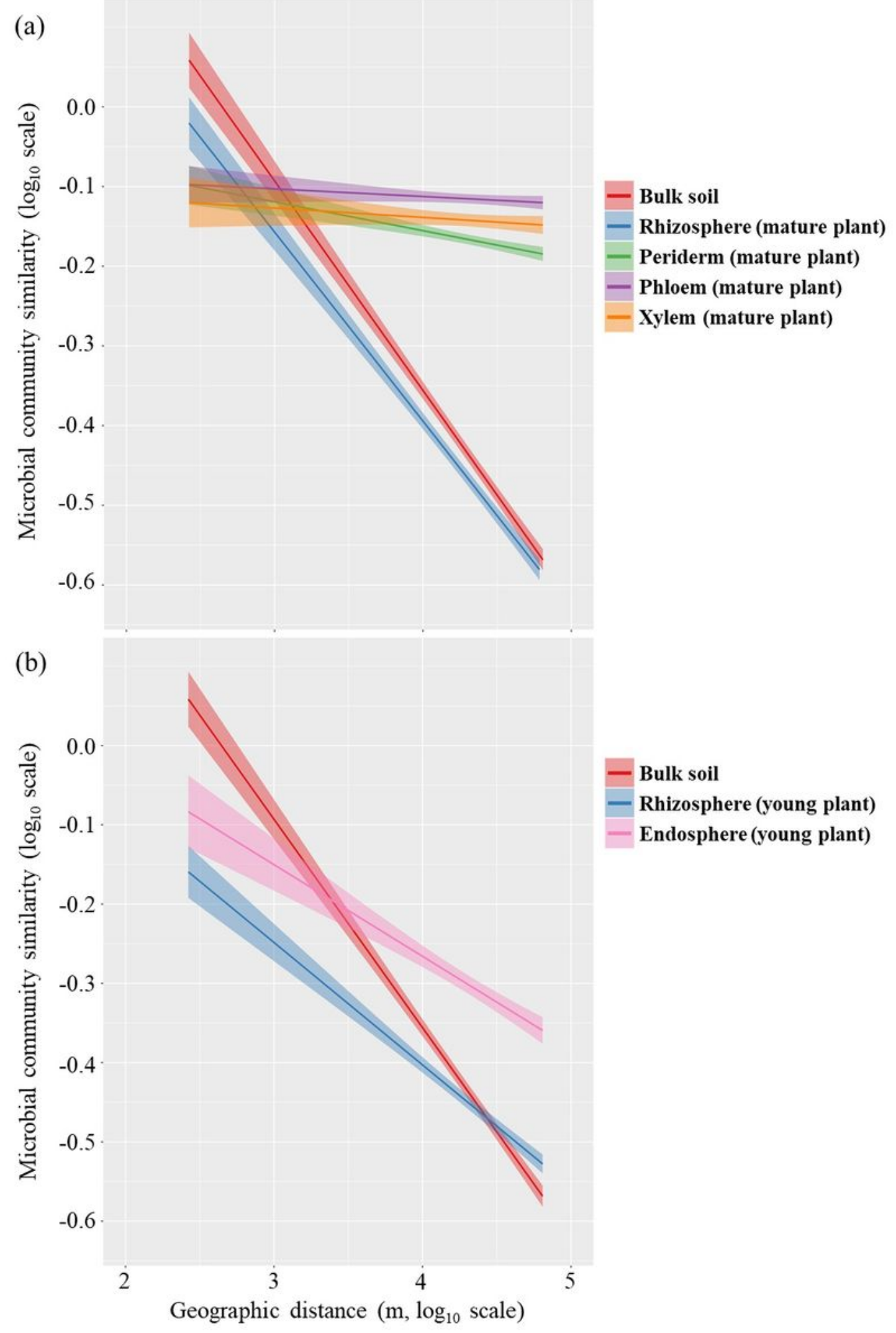

Figure 4

The effect of geographic location on microbial composition in soil and root niches of Melilotus officinalis The distance-decay relationship between microbiome similarity and geographic distance between 
sampled sites was tested in (a) mature plants and (b) young plants, respectively. The regression line is presented with $95 \%$ confidence intervals.

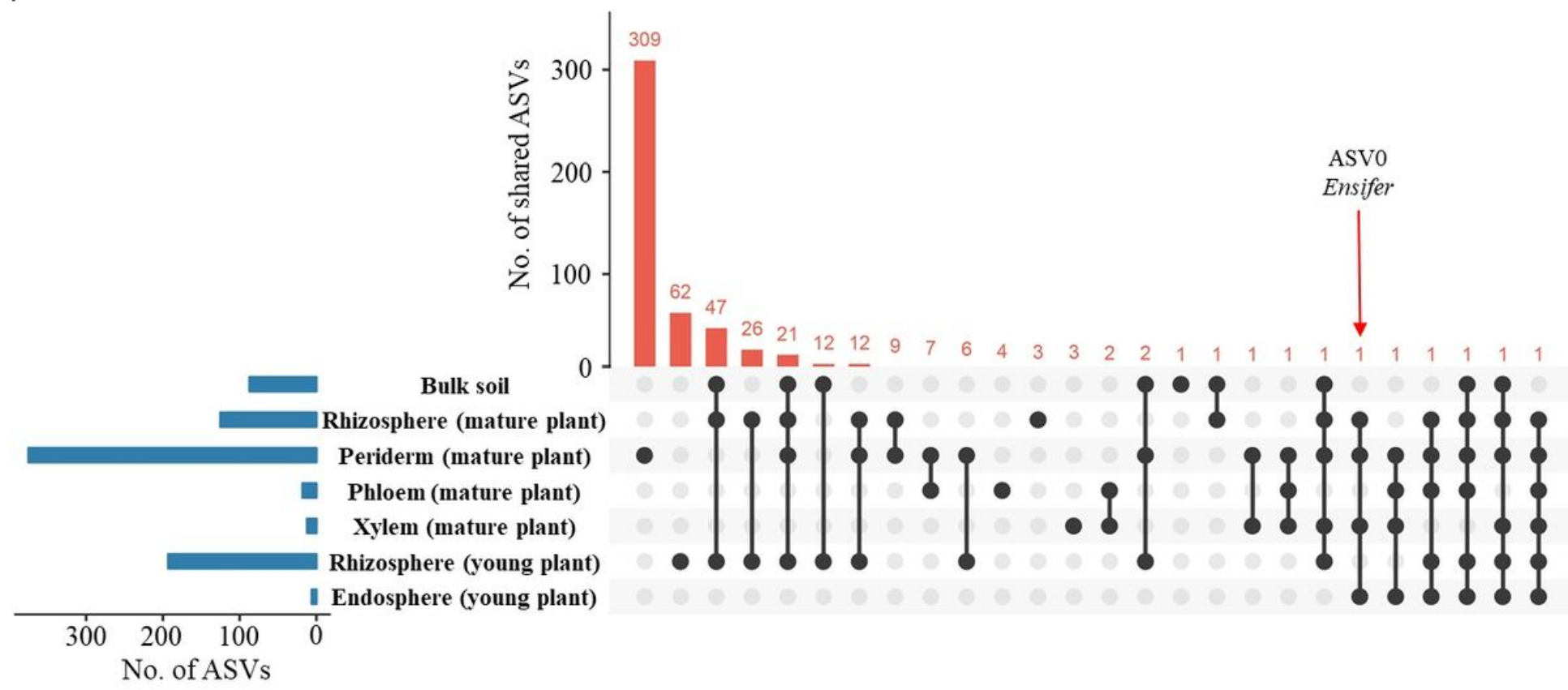

\section{Figure 5}

Core root-associated microbiomes of Melilotus officinalis The comparison of core ASVs between bulk soil, and root-associated microhabitats of mature plants (rhizosphere, periderm, phloem and xylem) and young plants (rhizosphere and endosphere). Core ASVs are defined as the ASVs present at $>70 \%$ of all sampled sites, and with the relative abundance ranked in the top $10 \%$. 
(a)

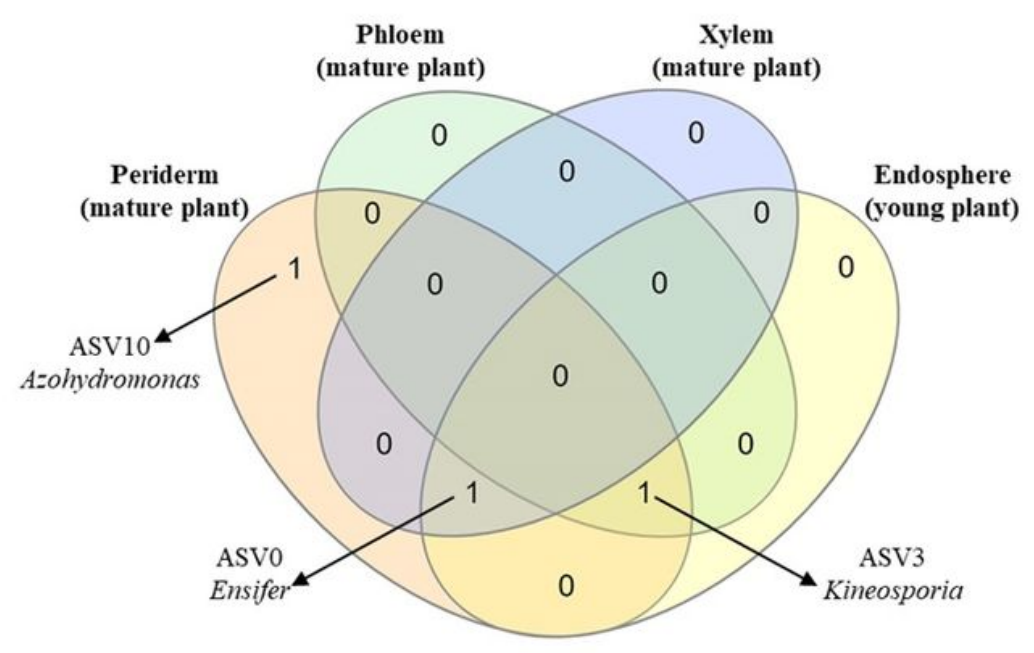

(b)

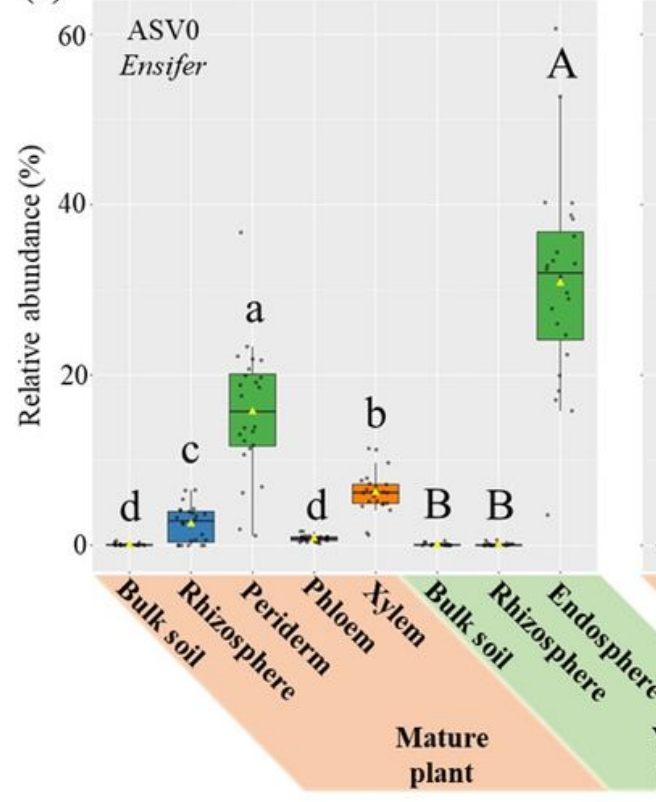

ASV3

Kineosporia (c)

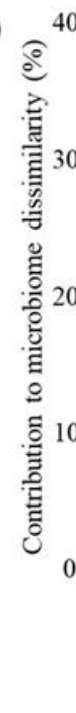

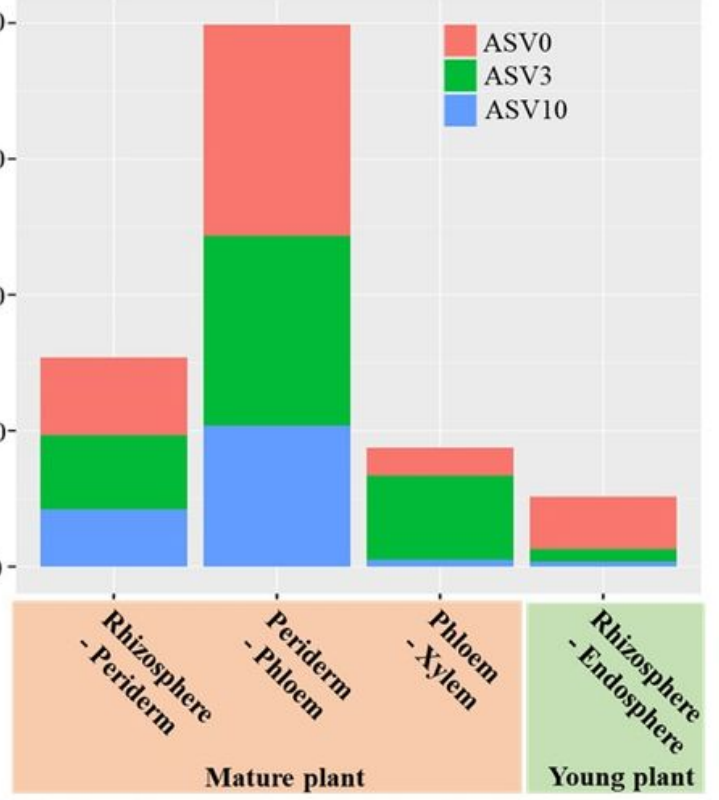

ASV10

Azohydromonas

\section{Figure 6}

The dominant ASVs in root-associated niches of Melilotus officinalis mature and young plants. (a) Three dominant ASVs were found only in the niches of root tissues. Among core ASVs of one niche, those with $>5 \%$ relative abundance at every site where they were present were selected as the dominant ASVs. (b) Relative abundance of the three dominant ASVs across all the studied niches. The values of individual samples are presented in the boxplot. The yellow triangle is the mean, and the box and central line represent first quartiles, medians, and third quartiles, respectively. The same lowercase / uppercase letters indicate no significant differences between niches within mature / young plants based on the adjusted $\mathrm{P}$ $<0.05$ using the Benjamini-Hochberg FDR method. (c) Contributions of the three dominant ASVs to the microbiome dissimilarity between two neighbouring niches, based on the similarity percentage analysis. 
(a)

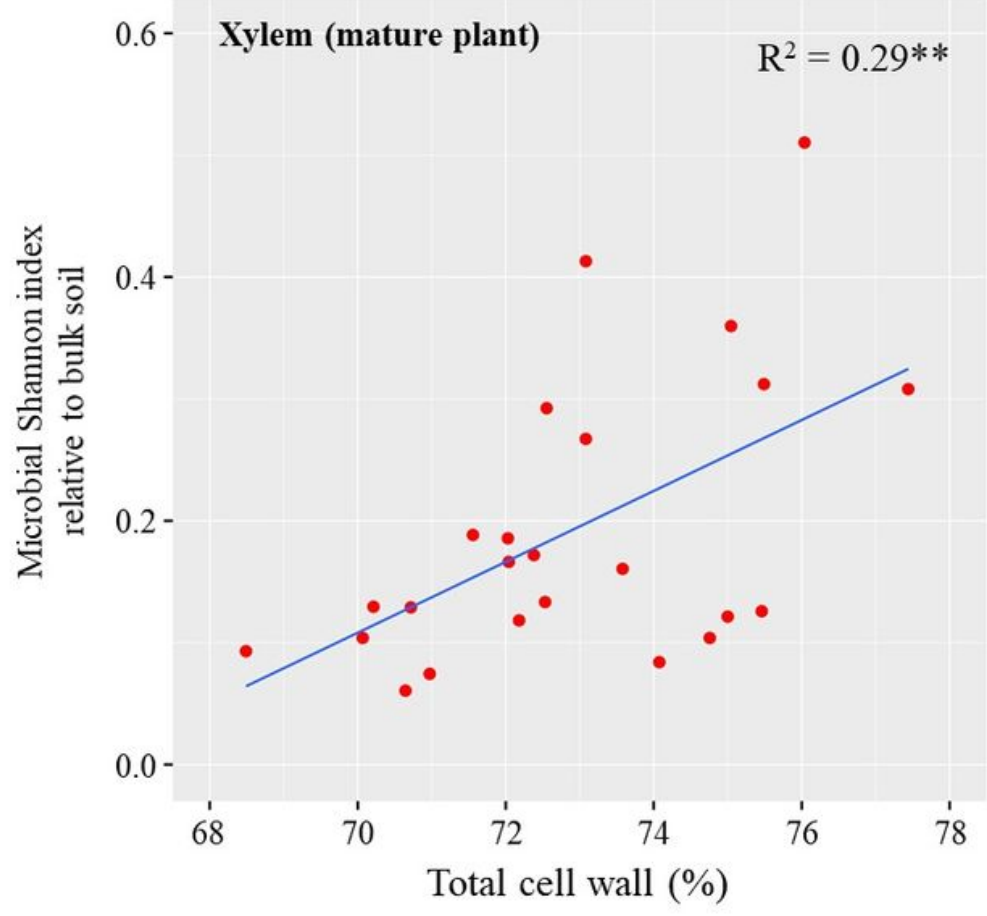

(b)

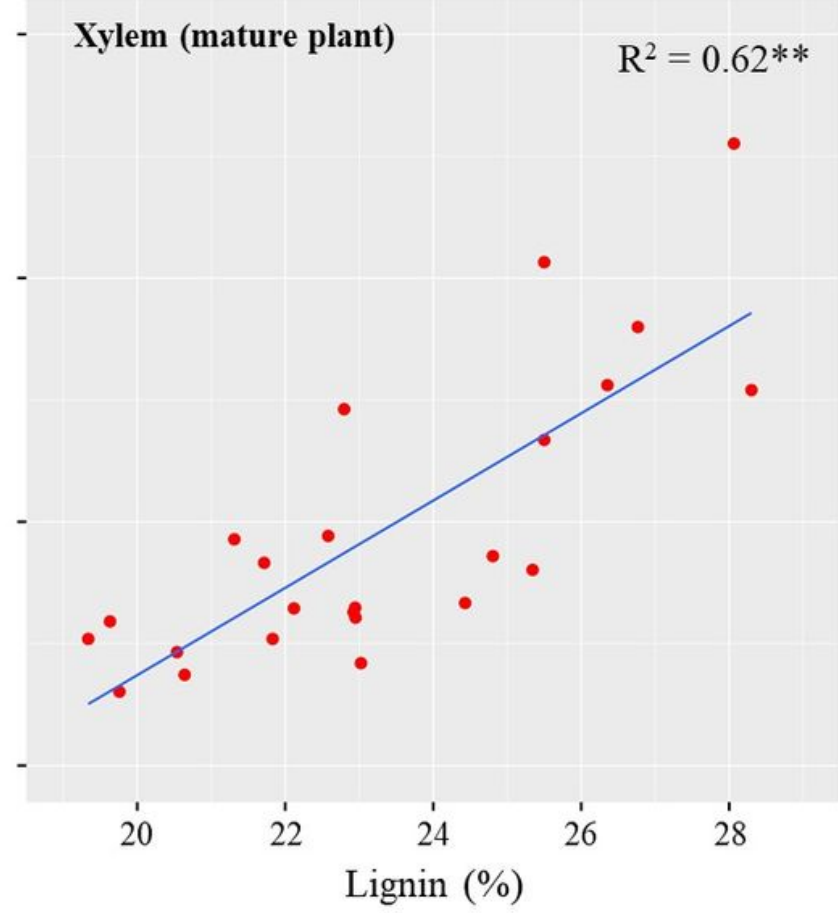

\section{Figure 7}

Correlations between microbiome diversity and cell wall component composition in the xylem of Melilotus officinalis Cell wall components included (a) total cell wall and (b) lignin content. ** indicates significant correlation at $\mathrm{P}<0.01$.

\section{Supplementary Files}

This is a list of supplementary files associated with this preprint. Click to download.

- Additionalfile1.docx

- Additionalfile2.xIsx 